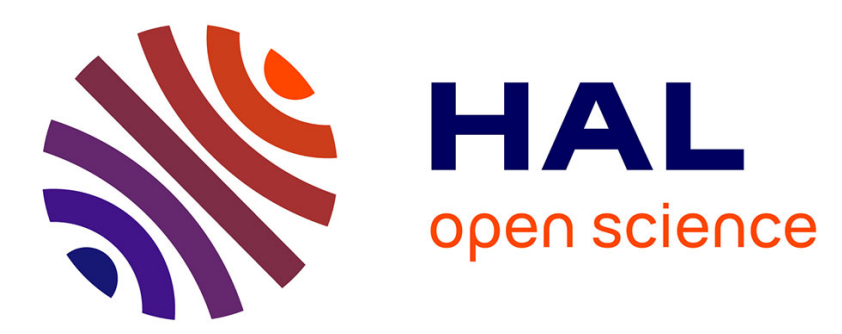

\title{
Predictors of persistent maternal depression trajectories in early childhood: results from the EDEN mother-child cohort study in France
}

J. van Der Waerden, C. Galéra, M.-J. Saurel-Cubizolles, A.-L. Sutter-Dallay, M. Melchior

\section{To cite this version:}

J. van Der Waerden, C. Galéra, M.-J. Saurel-Cubizolles, A.-L. Sutter-Dallay, M. Melchior. Predictors of persistent maternal depression trajectories in early childhood: results from the EDEN mother-child cohort study in France. Psychological Medicine, 2015, 45 (9), pp.1999-2012. 10.1017/S003329171500015X . hal-01286113

\section{HAL Id: hal-01286113 \\ https://hal.sorbonne-universite.fr/hal-01286113}

Submitted on 10 Mar 2016

HAL is a multi-disciplinary open access archive for the deposit and dissemination of scientific research documents, whether they are published or not. The documents may come from teaching and research institutions in France or abroad, or from public or private research centers.
L'archive ouverte pluridisciplinaire HAL, est destinée au dépôt et à la diffusion de documents scientifiques de niveau recherche, publiés ou non, émanant des établissements d'enseignement et de recherche français ou étrangers, des laboratoires publics ou privés. 


\section{Predictors of persistent maternal depression trajectories in early childhood:}

\section{results from the EDEN mother-child cohort study in France}

Judith van der Waerden, $\mathrm{PhD}{ }^{\mathrm{ab} \text { * }}$

Cédric Galéra, MD, PhD ${ }^{\text {cde }}$

Marie-Josèphe Saurel-Cubizolles, $\mathrm{PhD}^{\text {bf }}$

Anne-Laure Sutter-Dallay, MD, PhD dgh

Maria Melchior, ScD ab

and The EDEN Mother-Child Cohort Study Group ${ }^{1}$

${ }^{a}$ INSERM UMR_S 1136, Pierre Louis Institute of Epidemiology and Public Health, Department of Social Epidemiology, F-75013 Paris, France

${ }^{\mathrm{b}}$ Sorbonne Universités, UPMC Univ Paris 06, F-75005 Paris, France

${ }^{\mathrm{c}}$ Department of Child and Adolescent Psychiatry, Charles Perrens Hospital, F-33000 Bordeaux, France

${ }^{\mathrm{d}}$ Bordeaux University, F-33000 Bordeaux, France

${ }^{\mathrm{e}}$ INSERM U897, Center for Research in Epidemiology and Biostatistics, Prévention et Prise en Charge des Traumatismes, F-33000 Bordeaux, France

${ }^{f}$ INSERM, UMR_S 953, Epidemiological Research on Perinatal Health and Women's and Children's Health,

F-94807 Villejuif, France

${ }^{\mathrm{g}}$ INSERM U657, F-33000 Bordeaux

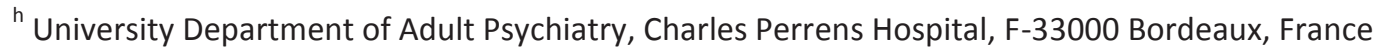

Corresponding author: Judith van der Waerden

Pierre Louis Institute of Epidemiology and Public Health, INSERM \& Sorbonne Universités UPMC

Hôpital Paul-Brousse, Bâtiment 15

16 avenue Paul Vaillant Couturier, 94807 VILLEJUIF CEDEX, France

judith.van-der-waerden@inserm.fr, Tel: +33(0)1 777474 31/ Fax: +33 (0)1 45595080 
${ }^{1}$ The EDEN Mother-Child Cohort Study Group includes I. Annesi-Maesano, J. Botton, M.A. Charles, P. DargentMolina, B. de Lauzon-Guillain, P. Ducimetière, M. de Agostini, B. Foliguet, A. Forhan, X. Fritel, A. Germa, V. Goua, R. Hankard, B. Heude, M. Kaminski, B. Larroque, N. Lelong, J. Lepeule, G. Magnin, L. Marchand, C. Nabet, R. Slama, M.J. Saurel-Cubizolles, M. Schweitzer, O. Thiebaugeorge

Word count: 4572

\section{Financial support}

We acknowledge all funding sources for the EDEN study: Fondation pour la Recherche Médicale (FRM), French Ministry of Research: IFR Program, INSERM Human Nutrition National Research Program, and Diabetes National Research Program (through a collaboration with the French Association of Diabetic Patients (AFD)), French Ministry of Health, French Agency for Environment Security (AFSSET), French National Institute for Population Health Surveillance (InVS), Paris-Sud University, French National Institute for Health Education (INPES), Nestlé, Mutuelle Générale de I'Education Nationale (MGEN), French speaking association for the study of diabetes and metabolism (ALFEDIAM), National Agency for Research (ANR nonthematic programme), National Institute for Research in Public Health (IRESP: TGIR Cohorte Santé 2008 programme).

This study was funded by the French National Research Agency (ANR, Program on Social Determinants of Health). The funding agencies had no role in the design and conduct of the study; in the collection, management, analysis, and interpretation of the data; and preparation, review, or approval of the manuscript. 


\section{Abstract \\ Background}

Maternal depression in the pre and postpartum period may set women on a course of chronic depressive symptoms. Little is known about predictors of persistently elevated depressive symptoms in mothers from pregnancy onwards. The aims of this study are to determine maternal depression trajectories from pregnancy to the child's fifth birthday and identify associated risk factors.

\section{Methods}

1807 mothers from the EDEN mother-child birth cohort study based in France (2003-2011) were followed from 24-28 weeks of pregnancy to their child's fifth birthday. Maternal depression trajectories were determined with a semi parametric group-based modeling strategy. Socio demographic, psychosocial and psychiatric predictors were explored for their association with trajectory class membership.

\section{Results}

Five trajectories of maternal symptoms of depression from pregnancy onwards were identified: no symptoms (60.2\%); persistent intermediate-level depressive symptoms (25.2\%); persistent high depressive symptoms (5.0\%); high symptoms in pregnancy only (4.7\%); high symptoms in the child's preschool period only (4.9\%). Socio-demographic predictors associated with persistent depression were non-French origin; psychosocial predictors were childhood adversities, life events during pregnancy and work overinvestment; psychiatric predictors were previous mental health problems, psychological help, and high anxiety during pregnancy.

\section{Conclusions}

Persistent depression in mothers of young children is associated to several risk factors present prior to or in pregnancy, notably anxiety. These characteristics precede depression trajectories and offer a possible entry point to enhance mother's mental health and reduce its burden on children. 


\section{Introduction}

Depression is a common mental health problem among women of childbearing age, with prevalence rates ranging from 10 to 32\% (Ertel et al. 2011; Wang et al. 2011). The impact of depression is significant not only for women's quality of life (Darcy et al. 2011), but also for their children's developmental outcomes (Ertel et al. 2011; Turney, 2012). Most information on the occurrence of maternal depression comes from studies conducted during the perinatal period (pregnancy to 12 months after delivery) (Horwitz et al. 2009), although symptoms may persist or reemerge later (Essex et al. 2001; Goodman, 2007), setting women on a course of chronic depressive symptoms which have especially deleterious consequences for children (Connelly et al. 2010; Fihrer et al. 2009; Turney, 2012).

Risk factors for maternal depression (such as socio-economic disadvantage, a prior history of mental disorders, stressful life events, poor social support, domestic violence, and pregnancy/ obstetric complications) have been well examined in the perinatal period (Koleva et al. 2011; O'Hara \& McCabe, 2013; Seimyr et al. 2013). Yet, little is known about predictors of persistent depression in mothers. With few exceptions (Giallo et al. 2014; Horwitz et al. 2009; Seto et al. 2005; Skipstein et al. 2010; 2012; Wang et al. 2011; Woolhouse et al. 2014), longitudinal studies examining chronic mental health difficulties in women beyond the second-year postpartum are scarce. These studies found that depressive symptoms are disproportionately likely to persist in women who are young, belong to an ethnic minority group, are unemployed, have low social support, experience high parenting stress, and stressful life events. However, most initial data collection was conducted 10 to 20 years ago and there is need for contemporary data on this topic. With the exception of the work by Woolhouse et al (2014), none of these studies included depressive symptoms occurring in pregnancy, even though these are prevalent (12.4\%) and associated with risk of later depression (Banti et al. 2011; Gaillard et al. 2014; Vliegen et al. 2014).

In order to gain better understanding of women's longitudinal patterns of depression and associated early risk factors we focused on antenatal predictors for persistent maternal depression 
from pregnancy onwards. We used data from a community-based sample of mothers followed from pregnancy up to when the child was five years of age to 1 ) determine symptom trajectories; 2 ) identify socio-demographic, psychosocial and psychiatric predictors of maternal depression trajectories present before or during pregnancy.

\section{Methods}

\section{$\underline{\text { Participants }}$}

Data for this study come from the EDEN mother-child study, set up to assess the pre- and postnatal nutritional, social, and environmental determinants of infant and child development and health (Drouillet et al. 2009). Pregnant women were recruited before 24 weeks of gestation from two maternity wards (Poitiers and Nancy University hospitals in France) between September 2003 and January 2006. Exclusion criteria were multiple pregnancies, history of diabetes, inability to speak and read French or plans to move out of the study region within the next 3 years. Among eligible women, $55 \%$ agreed to participate. Of the 2002 women recruited during pregnancy, birth data were available for 1899 mother-infant pairs. From pregnancy onwards, mothers and children were followed nine times (pregnancy, birth, 4, 8, 12, 24 months, 3, 4 and 5 years) via face-to-face or self-completed questionnaires completed by the mothers. Data on the child's birth characteristics were collected directly from medical records.

By the year 5 follow-up, data on maternal depression were available for 1190 participants. Attrition rates were highest for mothers who were of non-French origin, young, had low educational level, and at baseline were single, unemployed, had financial difficulties or experienced other life events, had low social support, reported childhood adversity, used tobacco, had a history of mental health problems. The study was approved by the Comité Consultatif de Protection des Personnes dans la Recherche Biomedicale (Ethics Committee, Kremlin Bicêtre Hospital) and by the Commission Nationale de l'Informatique et des Libertés (National Committee for Processed Data and Freedom 
(CNIL)). Written consent was obtained from the mother for herself at inclusion and for her newborn child after delivery.

\section{Measures and procedures}

Maternal symptoms of depression

Depressive symptoms during pregnancy and at 3 and 5 years follow-ups were assessed using the Center for Epidemiological Studies Depression (CES-D) questionnaire (Radloff, 1977). This previously validated 20-item questionnaire measures the number of depressive symptoms over the past week (score ranging 0-60) (Fuhrer \& Rouillon, 1989; Joiner et al. 2005). A threshold of $\geq 16$ is commonly used to identify individuals at risk for clinical depression.

Depressive symptoms during the first year after the child's birth $(4,8$ and 12 months postpartum) were assessed using the Edinburgh Postnatal Depression Scale (EPDS), a 10-item questionnaire designed to detect postnatal depression (score ranging 0-30) (Cox et al. 1987). In this study we used the cut-off $\geq 12$, which has been recommended for the French translation and has demonstrated its validity for research purposes (Guedeney \& Fermanian, 1998; Teissedre \& Chabrol, 2004).

To identify trajectories of maternal depressive symptoms we needed to meaningfully combine the scores of both instruments, which have different possible symptom severity score ranges. Thus, the scores for each instrument were standardized to t-scores $(M=50, S D=10)$, which allowed us to study them jointly as continuous measures.

\section{Predictors}

Based on the scientific literature we identified several socio demographic, psychosocial and psychiatric characteristics potentially associated with maternal depression trajectories. Socio demographic characteristics were: study center (Poitiers vs. Nancy), age (dichotomized at the sample mean $<30$ vs. $\geq 30$ years), country of birth (France vs. other), family situation (single vs. 
married/cohabitating), number of children, maternal educational level ( $<12 \mathrm{vs.} \geq 12$ years), maternal employment at the beginning of pregnancy (yes vs. no), partner's educational level ( $<12$ vs. $\geq 12$ years), partner's employment (yes vs. no), financial difficulties (any of the following (yes vs. no); difficulties to feed or clothe the family, difficulties to pay the rent, heating or electricity, regular overdraft of bank account, subsided health coverage). Psychosocial characteristics included negative life events that were assessed using a 17-item measure including major life events such as moving house, separation or divorce, death or serious illness of a close friend or family member, or legal troubles. Endorsed items were totaled to create an overall score (hypothetical range 0-17). As a large part of the sample (80\%) did not experience any events, scores were dichotomized for any life event occurrence (yes vs. no). Work related stress and work-related over commitment were measured with the Effort-Reward Imbalance (ERI) scale (Siegrist et al. 2004). The standard ERI questionnaire comprises 46 items measuring efforts (including work obligations and physical demands of the job) and rewards (including financial compensation, job security, personal and social recognition). Responses for each scale are summed and a categorical score for Effort-reward imbalance is calculated (yes vs. no). The over-commitment scale includes items such as "As soon as I get up in the morning I start thinking about work problems", and "People close to me say that I sacrifice too much for my job." These are scored on a four-point response scale, giving a range from 6 to 24 ; this scale is divided into the upper third of the distribution versus the rest (yes vs. no). Additional psychosocial risks included at least one maternal childhood adversity experienced prior to age 18 (material deprivation, parental conflict or violence, child abuse or neglect, placement out of home; yes vs. no), partner's substance use (tobacco, alcohol or cannabis use; yes vs. no), social support (yes vs. no). Psychiatric characteristics included: childhood behavior problems (yes vs. no), previous mental health problems (yes vs. no), pre-pregnancy mental health treatment (yes vs. no), pre-pregnancy substance use (tobacco, alcohol or cannabis use; yes vs. no), and anxiety in pregnancy (STAl score (Spielberger et al., 1983) dichotomized at the $80^{\text {th }}$ centile, $<17$ vs. $\geq 18$ ). 


\section{Statistical analyses}

Our aim was to identify trajectories of maternal depressive symptoms and associated predictors. We conducted a trajectory analysis, a semi parametric group-based modeling strategy used to identify homogeneous latent trajectory classes based on longitudinal data (Nagin, 1999, 2005).

Using the six scores of maternal depression available to us, we modeled maternal trajectories of depression using growth trajectory models (PROC TRAJ in SAS 9.3) under the censored normal distribution (Jones et al. 2001). Missing data were handled by PROC TRAJ under the missing-atrandom assumption, where individuals with missing information were assigned to their most likely group (Jones \& Nagin, 2007). The number and shapes of latent trajectories were determined using the Bayesian information Criteria (BIC) and refined by setting the trajectories' order (i.e. linear, quadratic, cubic). Using backward elimination of higher-order trajectories, a more parsimonious model was maintained whenever a higher-order growth coefficient did not reach statistical significance and the BIC value decreased. To define a good model, average posterior probabilities of trajectory membership should be at least equal to 0.7 for all groups (Nagin, 2005).

In the second stage of analysis, we used multinomial logistic regression analyses to test associations between predictors and trajectory groups (using the never depressed group as the reference). Variables were included in the final multivariate model if they were associated with class membership at $p<.10$ in bivariate logistic regression models. Our antenatal predictors of maternal depression trajectories were assessed at study baseline, resulting in very few covariates with missing data levels of $>2 \%$ (overall: $2.23 \%$ ). Exceptions were partner's substance abuse (9.5\% of data missing), work related stress and work-related over commitment ( $4.1 \%$ and $4.0 \%$ missing, respectively). Analyses were conducted with SPSS version 20.

\section{Results}

\section{$\underline{\text { Maternal depression trajectories }}$}

The study sample included 1807 mothers with sufficient data to estimate depression trajectories. 
The optimal number of maternal depression trajectories in our study was five. Average posterior probabilities of group membership were above 0.80 for all groups. The five trajectories of maternal depressive symptoms were as follows (Figure 1): $60.2 \%$ ( $n=1087$ ) of mothers had no symptoms; $4.7 \%$ $(n=85)$ had high symptoms in pregnancy only; $4.9 \%(n=89)$ had high symptoms in the child's preschool period only; $25.2 \%$ ( $n=456)$ had persistent intermediate-level symptoms and 5.0\% $(n=90)$ of mothers had persistent high-level symptoms. As expected, participants' symptoms at each wave of measurement were associated with the trajectory of depressive symptoms. Scores for persistent high-level symptoms were well above clinical cut-off scores for both depression measures (Table 1).

\section{Sample descriptives}

Table 2 presents participants' sociodemographic, psychosocial and psychiatric characteristics. Mothers were on average 30 years old at the time of the child's birth, mostly of French origin (95.7\%), 92.7\% were married or cohabitating and had on average 1 child. 54.2\% had at least 2 years of higher education, $83.9 \%$ were in paid employment at the beginning of pregnancy, $12.7 \%$ reported financial difficulties, 19.8\% experienced at least one negative life event during pregnancy and $29.3 \%$ reported childhood adversities. $14.6 \%$ reported work stress and $32.5 \%$ work overinvestment. $53.0 \%$ had a partner who used a psychoactive substance (mostly tobacco), while $3.8 \%$ experienced a lack of social support. Seven percent reported childhood behaviour problems and $10.7 \%$ previous mental health problems. 9.6\% received pre-pregnancy mental health treatment, 36.9\% reported prepregnancy substance use and $21.1 \%$ of mothers had symptoms of anxiety.

\section{Predictors of maternal depression trajectories}

Most socio demographic, psychosocial and psychiatric characteristics were associated with depression trajectories, with the exception of maternal age and family situation (Table 2). Table 3 presents the results (adjusted ORs) of multivariate regression analyses examining predictors of maternal depression trajectory. Compared to the no symptoms group, variables that were associated with depressive symptoms in pregnancy only included non-French origin (OR 4.94, 95\% Cl 
1.35-18.07), experience of childhood adversities (OR $2.49,95 \% \mathrm{Cl} 1.33-4.68$ ), lack of social support

(OR 4.31, 95\% Cl 1.52-12.25), history of mental health problems (OR 2.31, 95\% Cl 1.02-5.22), prepregnancy substance use (OR $2.27,95 \% \mathrm{Cl} 1.17-4.39)$ and anxiety during pregnancy (OR $11.97,95 \%$ $\mathrm{Cl}$ 6.42-22.31). Depressive symptoms in the child's preschool period only were associated with partner's low educational level (OR 1.99, 95\% Cl 1.09-3.65), pre-pregnancy mental health treatment (OR 2.58, 95\% $\mathrm{Cl} 1.18-5.65$ ) and anxiety during pregnancy (OR 3.89, 95\% $\mathrm{Cl}$ 2.17-6.99). Persistent intermediate-level depressive symptoms were associated with the experience of life events during pregnancy (OR 1.47, 95\% Cl 1.03-2.09), work overinvestment (OR 2.04, 95\% Cl 1.49-2.78), prepregnancy mental health treatment (OR $1.78,95 \% \mathrm{Cl} 1.09-2.93)$ and anxiety during pregnancy (OR 3.33, 95\% $\mathrm{Cl} 2.35-4.71)$. Finally, persistent high depressive symptoms were associated with nonFrench origin (OR 5.92, 95\% Cl 1.86-18.86), childhood adversities (OR 4.09, 95\% $\mathrm{Cl}$ 2.16-7.75), work overinvestment (OR $4.78,95 \% \mathrm{Cl} 2.23-10.23$ ), history of mental health problems (OR $3.78,95 \% \mathrm{Cl}$ 1.82-7.85) and anxiety during pregnancy (OR 7.94, 95\% Cl 4.29-14.69).

In additional analyses we tested whether the ORs of predictors associated with several trajectories significantly differed. This was the case for work overinvestment (OR for persistent highlevel symptoms significantly higher than that for persistent intermediate-level symptoms, $p=0.03$ ), and for anxiety (ORs for symptoms in pregnancy only significantly higher than for symptoms in preschool only $(p=.005)$ and persistent intermediate-level symptoms $(p<.0001)$, but not for persistent high-level symptoms ( $p=.304))$.

\section{Discussion}

\section{Main findings}

Using data from a large community based birth cohort study, we identified five distinct trajectory groups of maternal symptoms of depression from pregnancy through the child's 5th birthday (no symptoms: $60.2 \%$, high symptoms in pregnancy: $4.7 \%$, high symptoms in the child's preschool period: 4.9\%, persistent intermediate-level symptoms: $25.2 \%$ and persistent high-level symptoms: $5.0 \%$ ). 
Depression trajectories - in particular persistent symptoms - appeared especially strongly associated with women's psychosocial and psychiatric characteristics. Particularly, women who are anxious or who experience stressful work conditions during pregnancy may have an increased probability of persistent depressive symptoms over time. Women who present these characteristics may require specific monitoring during pregnancy and afterwards.

\section{Strengths and limitations}

The current study has several strengths such as a) a large community sample, b) longitudinal and repeated assessments of multiple demographic, psychosocial and psychiatric characteristics, c) the use of validated measures of maternal mental health. However, we also acknowledge limitations. First, maternal depressive symptoms were self-reported, using two different measures. However, both the CES-D and the EPDS, which we standardized to ensure comparability, have previously been validated and we were able to study the entire depression spectrum rather than diagnoses, which may be a closer estimate of variations in symptomatology at the population level and show higher reliability and validity (Markon et al. 2011). Second, we only included baseline predictors, possibly underestimating the influence of factors that can change over time (for example financial difficulties increased from $12.7 \%$ at baseline to $22.2 \%$ at 5 -year follow-up, $92.7 \%$ of women were married/ cohabitating compared to $88.5 \%$ after 5 years). Nevertheless, this approach allowed us to identify early risk factors that may set women on depressive symptom trajectories from pregnancy onwards. In addition, including baseline predictors might have led to inflation of the associations found between the high symptoms in pregnancy trajectory and possible risk factors due to shared method variance. However, most of the associated socio-demographic, psychosocial and psychiatric risk factors preceded the occurrence of depressive symptoms during pregnancy and are thus unlikely to be biased in this way. Finally, the present study sample is not nationally representative. Compared with a national perinatal survey performed in 2003 on a representative sample of French women (Blondel et al. 2006) the EDEN study was similar in age and proportion of unmarried couples but 
included a larger proportion of women with university level education (53 vs. 43\%) (Drouillet et al. 2008). This is further increased by selective attrition among socially disadvantaged women. As it is likely that this group has a higher proportion of maternal depression (Ertel et al. 2011), our results are plausibly an under- rather than an over-estimate of the relationship between socio-economic predictors and maternal depression trajectories. Replication of our findings in a population including a higher proportion of disadvantaged, high-risk families is warranted.

\section{Maternal depressive symptom trajectories}

Exploring maternal depressive symptoms and associated predictors during the early childhood period is important to improve our understanding of the variation in symptom severity and persistence and can clarify why the trajectories of some individuals differ from those of others. Using a trajectory modeling approach we were able to gain insight into five distinct patterns of depressive symptoms from pregnancy onwards. The majority (60.2\%) of mothers reported no or very few depressive symptoms across follow-up. This finding is consistent with previous studies, suggesting that most mothers do not experience elevated levels of depressive symptoms during and after the perinatal period (Mora et al. 2009; Sutter-Dallay et al. 2012).

We identified two groups of women with a marked increase in symptom scores in specific periods. As previously described, a small group of mothers (4.7\%) appear to experience depressive symptoms only during pregnancy (Mora et al. 2009; Vänskä et al. 2011). This may partly be due to measurement issues, as it is sometimes difficult to distinguish depressive symptoms from normal somatic symptoms experienced in pregnancy (e.g. changes in appetite and weight, sleep and energy). It has been suggested that, particularly during pregnancy, depression is best assessed by looking at cognitive-affective symptoms (Pereira et al. 2014). The CES-D, used to ascertain depressive symptoms in pregnancy in the EDEN study, mostly covers cognitive symptoms, therefore our measure is probably only moderately affected by such bias. It may be that a unique subgroup of women predominantly suffers from prenatal depression, which resolves post-natally. 
A third group of women (4.9\%) appear to have high symptoms in the child's preschool period only. Although the prevailing view is that women are especially vulnerable to depression in the perinatal period, maternal depression may actually be more common 4 to 5 years after a birth than at any time in the first 12 months postpartum (Najman et al. 2000; Woolhouse et al. 2014). This may be because child-rearing makes greater demands on the mother's mental health than the perinatal period itself (Betts et al. 2014). Contrary to some prior studies, we did not identify a group of women with symptoms exclusively in the postpartum period. It may be that a significant portion of women with postpartum-onset depression remain depressed beyond the child's first year, which would have lead them to them being assigned to one of the groups with persistent symptoms.

Indeed, in both groups of chronic depressive symptoms we noted a steady increase in symptom severity between 4 and 12 months postpartum. Thus, we identified a substantial group of mothers (25.2\%) with intermediate-level depressive symptoms throughout follow-up. Finally, consistent with prior research, a small group (5.0\%) of women had persistently high depressive symptoms, which were probably above a clinically significant threshold (Campbell et al. 2007; Cents et al. 2013; Mora et al. 2009; Vänskä et al. 2011). Although we could not determine how many of these women had diagnosable major depression, their CES-D and EPDS scores were well above established cut-off scores, indicating that their symptoms fall within a clinical range. Our results indicate that these chronic depression trajectories may already start in pregnancy and persist over time.

\section{Predictors of maternal depressive symptom trajectories}

Maternal depressive symptoms often occur within a context of personal and environmental risk, and the socio demographic, psychosocial and psychiatric predictors we studied were shared across various trajectories. The only predictor associated with an increased likelihood of depressive symptoms at any moment during follow-up was anxiety during pregnancy, with especially high associations with depression in pregnancy $(O R=11.97)$ and persistently high symptoms $(O R=7.94)$. 
Anxiety symptoms are frequently reported by pregnant women and often considered by midwives and obstetricians as part of the normal psychic experiences of pregnancy (Dunkel Schetter \& Tanner, 2012; Goodman \& Tyer-Viola, 2010). As depression and anxiety during pregnancy are moderately to highly comorbid (Heron et al. 2004; Wynter et al. 2013), it may be difficult to clearly attribute symptoms to one or the other condition (Skouteris et al. 2009). Yet, there is increasing evidence to suggest that antenatal anxiety symptoms form a clinical entity of their own, possible forming a cycle of co-morbidity, whereby initial levels of depressive symptoms lead to higher levels of anxiety, which in turn may then predict higher depressive symptoms (Skouteris et al. 2009; Sutter-Dallay et al. 2004). Recent studies have suggested that high levels of maternal anxiety during pregnancy could, independently from prenatal depression, predict an elevated risk of long-term depressive symptoms (Horwitz et al. 2007; Vänskä et al. 2011; Sutter-Dallay et al. 2012). However, to our knowledge prior studies had a shorter follow-up than our investigation. We are not aware of studies indicating that the impact of prenatal anxiety lasts even up to five years after birth.

Other variables were more uniquely associated with particular trajectory classes, with women with depressive symptoms in pregnancy only or persistently high depressive symptoms presenting the largest number of risk factors. This suggests that the cumulative effect of multiple risk factors may well increase the chronicity of maternal depressive symptoms, especially since overall there were very few predictor variables that were significantly more strongly related to one trajectory than any other. A specific predictor for depression in pregnancy was a lack of social support. Psychosocial and emotional resources are needed to adapt to the significant life changes associated with pregnancy and the early parenting period (Manuel et al. 2012). Insufficient support is negatively associated with maternal psychological well-being during pregnancy and increases the risk of depression, as well as worse health and pregnancy outcomes (Robertson et al. 2004; Orr, 2004; Elsenbruch et al. 2007). Women reporting any substance use (tobacco, alcohol or cannabis) before pregnancy also had an elevated likelihood $(\mathrm{OR}=2.27)$ for depressive symptoms during pregnancy. Many expectant mothers follow recommendations to maintain a healthy lifestyle during pregnancy, 
and they may have stopped or reduced their consummation (Viau et al., 2002). However, reducing or eliminating substance use by pregnant women has only inconsistently been found to be related to prenatal depressive symptoms (Solomon et al. 2006; Zhu \& Valbo, 2002). It is likely that women who continued their substance use in pregnancy have an increased vulnerability to mental health problems (Farrell et al. 2003; Le Strat et al. 2011).

Concerning the predictors of persistently elevated depressive symptoms in mothers from pregnancy onwards, previous studies have reported that maternal depression is associated with maternal age, income, relationship and employment status and educational attainment (e.g. Seimyr et al. 2013; Seto et al. 2005; Sutter-Dallay et al. 2011). Contrary to these reports, we found that socio demographic characteristics were not associated with depressive symptoms, with the exception of non-French origin. Migrant women had a high level of symptoms in pregnancy $(\mathrm{OR}=4.94)$ or persistently high symptoms $(O R=5.92)$. Pregnant migrant women may go unidentified and untreated due to underutilization of health services, and therefore, are at increased risk of persistent mental health difficulties (Giallo et al. 2014; Lindert et al. 2008). However, as previously indicated, the role of socio-economic predictors might be underestimated due to the relatively small proportion of socially disadvantaged women in our sample.

Psychosocial risk factors for persistent depression were the experience of childhood adversity. Our finding extends prior research that mostly focused on child abuse (Clark et al. 2010) (Leigh \& Milgrom, 2008). Additionally, we found an increased likelihood of depression in women who encountered life stressors during pregnancy. While pregnancy and birth are often regarded as stressful in their own right, many women have additional stressful experiences during pregnancy (Robertson et al. 2004; Giallo et al. 2014), which are consistently shown to be associated with women's increased vulnerability to post-partum depression (Rubertsson et al. 2005). Our results indicate that stressors in pregnancy are also associated with chronic maternal depression. Importantly, it appears that depression is not only associated with a high but also a moderate number of stressors (Liu \& Tronick, 2013). Finally, we found that work stress, and particularly work 
overinvestment, is associated with persistent depression, of both intermediate and high intensity. Prospective epidemiological studies show that overinvestment, that is an individual's need for approval and esteem at work, is associated with significantly elevated risks of depression (Clark et al. 2012; Siegrist, 2008). Pregnancy represents a dynamic period when both work conditions and worker assessment of occupational psychosocial stressors may change. Previous studies found that unskilled and low-waged occupations are often related to adverse employment conditions in pregnancy, including a lack of access to paid and unpaid parental leave. Women experiencing these working conditions are likely to experience greater work-related psychological distress than those who are more advantaged (Cooklin et al. 2007; Miyake et al. 2011). Yet, paid maternity leave is generally available in France (Ruhm \& Teague, 1998) and chi-square comparisons (data not shown) revealed that work overinvestment was not associated with women's socio-demographic characteristics, the type (manual or white collar) or duration (full or part-time) of work they exercised, nor their partner's employment status. It was however more common in women who reported financial difficulties. In addition to work stress, overinvestment may also capture an individuals' personality, characterized by low self-esteem and elements of Type A behavior (Clark et al. 2012; van Vegchel et al. 2005). It could well be that work overinvestment partly taps into these psychological constructs that have been found to be related to depression etiology. Our finding suggests that work-related stressors should more frequently be studied in the context of pre and postnatal depression, as worklife imbalance may contribute to mental health difficulties in certain women. In our sample, previous mental health problems and use of mental health services were independent psychiatric predictors of chronic depressive symptom trajectories, confirming earlier results (Seimyr et al. 2013; Giallo et al. 2014).

\section{Conclusion}

In the present study we found evidence that depressive symptom trajectories in mothers of young children are heterogeneous and vary with a number of preexisting characteristics. While most mothers do not have depressive symptoms, for some women maternal depression reaches its peak 
during pregnancy, in some during the preschool years while others follow a chronic course of symptoms, either of intermediate or high intensity. Women's trajectories of depressive symptoms may be changed when prevention or evidence-based treatment are implemented early on, during pregnancy or in the immediate postpartum. A recent review reported that psychosocial and psychological interventions, compared to usual postpartum care, were associated with a reduction in depressive symptomatology within the first 12 months postpartum (Dennis \& Dowswell, 2013). Promising interventions include the provision of intensive, professionally based postpartum home visits, telephone-based peer support, and interpersonal psychotherapy. All of the potential risk factors of long-term depressive symptoms can be identified during routine prenatal care and could contribute to early diagnosis. We recommend that clinicians be specifically attentive to the wellbeing of women who experience prenatal anxiety symptoms or work related stress. Nevertheless, proactive screening of psychosocial risks still remains a small part of prenatal care and less than $15 \%$ of pregnant and postpartum women receive adequate help (Austin et al. 2013; Coleman et al. 2008). Several psychosocial risk assessment tools, such as the Pregnancy Risk Questionnaire (Austin et al. 2005) or the Antenatal Psychosocial Health Assessment (Carroll et al. 2005), have been developed to assess pregnant women for the presence of psychosocial risk factors known to be associated with the onset of perinatal depression and anxiety. While some concerns remain about their psychometric properties (Johnson et al. 2012), it has been demonstrated that antenatal care providers (midwives, obstetricians, GPs) were more likely to detect concerns and identify a number of risk factors than providers who gave standard care (Austin et al. 2008). Identifying women at risk for persistent depressive symptoms, through screening for multiple psychosocial risk indicators during pregnancy, may facilitate interventions targeting risks for maternal mental health problems and associated problematic early child development.

\section{Conflict of interest}

None 


\section{Ethical standards}

The authors assert that all procedures contributing to this work comply with the ethical standards of the relevant national and institutional committees on human experimentation and with the Helsinki Declaration of 1975, as revised in 2008. 
Figure 1 Trajectories of maternal symptoms of depression by child's age in months in the EDEN cohort study ( $n=1807,2003-2011$, France)

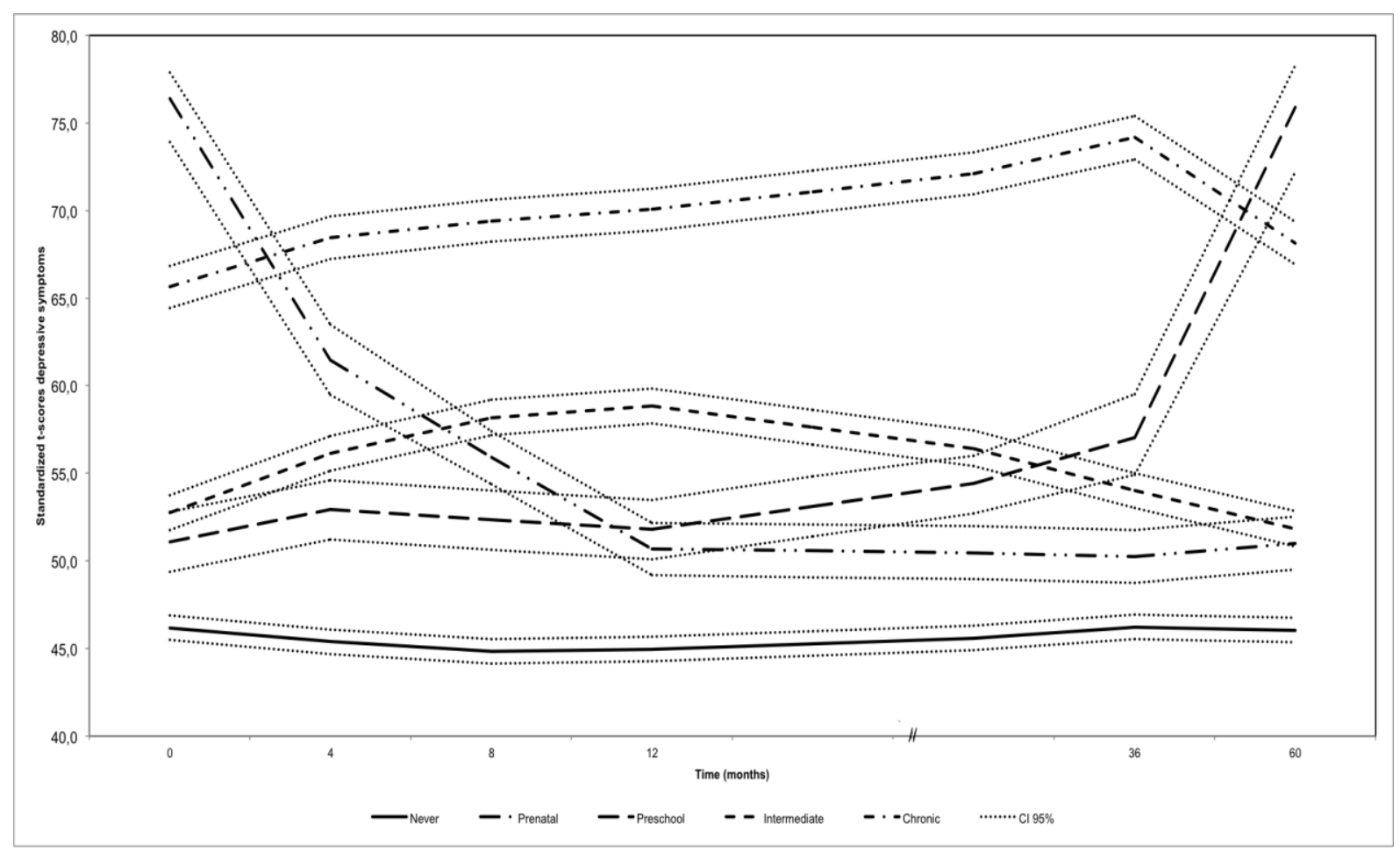




\begin{tabular}{|c|c|c|c|c|c|c|}
\hline Time (months) & $\mathbf{0}$ & 4 & 8 & 12 & 36 & 60 \\
\hline & CES-D & EPDS & EPDS & EPDS & CES-D & CES-D \\
\hline No symptoms & $8.59(5.55)$ & $3.02(2.97)$ & $2.53(2.57)$ & $2.23(2.44)$ & $6.44(4.79)$ & $5.99(4.50)$ \\
\hline High symptoms in pregnancy only & $31.88(8.74)$ & $11.35(6.27)$ & $8.72(5.78)$ & $6.81(4.36)$ & $7.93(5.54)$ & $10.97(6.01)$ \\
\hline High symptoms in preschool period only & $11.94(5.79)$ & $6.05(3.81)$ & $5.34(3.09)$ & $5.29(3.86)$ & $18.34(9.84)$ & $26.48(9.45)$ \\
\hline Intermediate-level symptoms level & $13.92(6.00)$ & $8.38(4.13)$ & $8.61(4.03)$ & $8.31(4.08)$ & $13.53(7.22)$ & $11.39(5.65)$ \\
\hline Persistent high depressive symptoms & $24.12(8.58)$ & $14.61(5.71)$ & $14.61(5.16)$ & $15.00(5.39)$ & $29.73(9.14)$ & $24.22(9.72)$ \\
\hline
\end{tabular}




\begin{tabular}{|c|c|c|c|c|c|c|c|}
\hline & $\begin{array}{c}\text { Overall } \\
\text { sample } \\
\text { ( } n=1807)\end{array}$ & $\begin{array}{c}\text { No symptoms } \\
(n=1087)\end{array}$ & $\begin{array}{l}\text { Pregnancy } \\
\text { only }(n=85)\end{array}$ & $\begin{array}{l}\text { Preschool } \\
\text { only }(n=89)\end{array}$ & $\begin{array}{c}\text { Intermediate } \\
(n=456)\end{array}$ & $\begin{array}{c}\text { Persistent } \\
\text { high }(n=90)\end{array}$ & \\
\hline & $\begin{array}{c}N(\%) \\
\text { Mean (sd) }\end{array}$ & $\begin{array}{c}N(\%) \\
\text { Mean }(s d)\end{array}$ & $\begin{array}{c}N(\%) \\
\text { Mean }(s d)\end{array}$ & $\begin{array}{c}N(\%) \\
\text { Mean (sd) }\end{array}$ & $\begin{array}{c}N(\%) \\
\text { Mean }(s d)\end{array}$ & $\begin{array}{c}N(\%) \\
\text { Mean }(s d)\end{array}$ & Pvalue \\
\hline \multicolumn{8}{|l|}{ Sociodemographic } \\
\hline Age at birth (years) & & & & & & & .480 \\
\hline$<30$ & 906 (50.4\%) & $540(49.8 \%)$ & $43(52.4 \%)$ & $38(42.7 \%)$ & $239(52.8 \%)$ & 46 (51.7\%) & \\
\hline$\geq 30$ & $892(49.6 \%)$ & $545(50.2 \%)$ & $39(47.6 \%)$ & $51(57.3 \%)$ & $214(47.2 \%)$ & $43(48.3 \%)$ & \\
\hline Country of origin & & & & & & & $<0.001$ \\
\hline France & $1729(95.7 \%)$ & $1054(97.0 \%)$ & $7588.2 \%$ & $86(96.6 \%)$ & 435 (95.4\%) & $79(87.8 \%)$ & \\
\hline Other & $78(4.3 \%)$ & $33(3.0 \%)$ & $10(11.8 \%)$ & $3(3.4 \%)$ & $21(4.6 \%)$ & $11(12.2 \%)$ & \\
\hline \multicolumn{8}{|l|}{ Family situation } \\
\hline Single & $131(7.3 \%)$ & $65(6.0 \%)$ & $8(9.6 \%)$ & $8(9.0 \%)$ & $41(9.1 \%)$ & $9(10.0 \%)$ & .153 \\
\hline Married/Cohabitating & $1662(92.7 \%)$ & $1014(94.0 \%)$ & 75 (90.4\%) & $81(91.0 \%)$ & 411 (90.9\%) & $81(90.0 \%)$ & \\
\hline Number of children & $.96(.84)$ & $.93(.83)$ & $1.10(.71)$ & $1.04(.91)$ & $.95(.85)$ & $1.20(.88)$ & .063 \\
\hline Educational level & & & & & & & $<0.001$ \\
\hline$<12$ & $813(45.8 \%)$ & $429(40.2 \%)$ & $48(59.3 \%)$ & 49 (55.1\%) & $230(51.2 \%)$ & $57(63.3 \%)$ & \\
\hline$\geq 12$ & 964 (54.2\%) & $639(59.8 \%)$ & $33(40.7 \%)$ & $40(44.9 \%)$ & $219(48.8 \%)$ & $33(36.7 \%)$ & \\
\hline Employment & & & & & & & .011 \\
\hline No & 290 (16.1\%) & $156(14.4 \%)$ & $17(20.2 \%)$ & $16(18.0 \%)$ & 76 (16.7\%) & $25(27.8 \%)$ & \\
\hline Yes & $1516(83.9 \%)$ & $931(85.6 \%)$ & $67(79.8 \%)$ & $73(82.0 \%)$ & $380(83.3 \%)$ & 65 (72.2\%) & \\
\hline Educational level partner & & & & & & & .001 \\
\hline$<12$ & $924(52.3 \%)$ & $521(48.8 \%)$ & 54 (65.1\%) & $55(63.2 \%)$ & 241 (54.6\%) & $53(60.9 \%)$ & \\
\hline$\geq 12$ & $842(47.7 \%)$ & 547 (51.2\%) & 29 (34.9\%) & $32(36.8 \%)$ & $200(45.4 \%)$ & 34 (39.1\%) & \\
\hline Employment partner & & & & & & & .004 \\
\hline No & $138(7.9 \%)$ & $68(6.4 \%)$ & $11(13.8 \%)$ & 7 (8.1\%) & $38(8.6 \%)$ & $14(16.1 \%)$ & \\
\hline Yes & $1617(92.1 \%)$ & $993(93.6 \%)$ & 69 (86.2\%) & 79 (91.9\%) & 403 (91.4\%) & $73(83.9 \%)$ & \\
\hline Financial difficulties & & & & & & & $<0.001$ \\
\hline No & $1568(87.3 \%)$ & $990(91.7 \%)$ & $61(73.5 \%)$ & 75 (84.3\%) & 379 (83.5\%) & $63(70.0 \%)$ & \\
\hline Yes & $228(12.7 \%)$ & $90(8.3 \%)$ & $22(26.5 \%)$ & $14(15.7 \%)$ & 75 (16.5\%) & $27(30.0 \%)$ & \\
\hline \multicolumn{8}{|l|}{ Psychosocial } \\
\hline $\begin{array}{l}\geq 1 \text { Life events during } \\
\text { pregnancy }\end{array}$ & & & & & & & $<0.001$ \\
\hline No & $1400(80.2 \%)$ & $890(84.0 \%)$ & $53(69.7 \%)$ & $66(76.7 \%)$ & 328 (75.1\%) & $63(72.4 \%)$ & \\
\hline Yes & $345(19.8 \%)$ & $169(16.0 \%)$ & $23(30.3 \%)$ & $20(23.3 \%)$ & $109(24.9 \%)$ & $24(27.6 \%)$ & \\
\hline Work related stress & & & & & & & .067 \\
\hline No & $1139(85.4 \%)$ & 734 (87.5\%) & $44(86.3 \%)$ & $52(83.9 \%)$ & $268(81.0 \%)$ & $41(82.0 \%)$ & \\
\hline Yes & $194(14.6 \%)$ & $105(12.5 \%)$ & $7(13.7 \%)$ & $10(16.1 \%)$ & $63(19.0 \%)$ & $9(18.0 \%)$ & \\
\hline Work overinvestment & & & & & & & $<0.001$ \\
\hline No & 901 (67.5\%) & $628(74.8 \%)$ & $30(58.8 \%)$ & $43(68.3 \%)$ & $182(55.0 \%)$ & $18(36.0 \%)$ & \\
\hline Yes & $434(32.5 \%)$ & $212(25.2 \%)$ & $21(41.2 \%)$ & $20(31.7 \%)$ & $149(45.0 \%)$ & $32(64.0 \%)$ & \\
\hline$\geq 1$ Childhood adversity & & & & & & & $<0.001$ \\
\hline No & $1272(70.7 \%)$ & 826 (76.3\%) & $40(48.2 \%)$ & $58(65.2 \%)$ & $310(68.1 \%)$ & $38(42.2 \%)$ & \\
\hline Yes & $527(29.3 \%)$ & $256(23.7 \%)$ & $43(51.8 \%)$ & $31(34.8 \%)$ & 145 (31.9\%) & $52(57.8 \%)$ & \\
\hline Partner any substance use & & & & & & & .007 \\
\hline No & $768(47.0 \%)$ & $437(43.6 \%)$ & 39 (55.7\%) & $40(49.4 \%)$ & 208 (51.2\%) & $44(58.7 \%)$ & \\
\hline Yes & $866(53.0 \%)$ & $565(56.4 \%)$ & 31 (44.3\%) & $41(50.6 \%)$ & $198(48.8 \%)$ & 31 (41.3\%) & \\
\hline Social support & & & & & & & $<0.001$ \\
\hline No & $68(3.8 \%)$ & $30(2.8 \%)$ & $13(15.9 \%)$ & $2(2.3 \%)$ & $14(3.1 \%)$ & 9 (10.1\%) & \\
\hline Yes & 1718 (96.2\%) & 1047 (97.2\%) & 69 (84.1\%) & 86 (97.7\%) & 436 (96.9\%) & $80(89.9 \%)$ & \\
\hline
\end{tabular}




\begin{tabular}{|c|c|c|c|c|c|c|c|}
\hline \multicolumn{8}{|l|}{ Psychiatric } \\
\hline Childhood behavior problems & & & & & & & $<0.001$ \\
\hline No & $1657(92.7 \%)$ & $1025(95.2 \%)$ & $71(85.5 \%)$ & 79 (90.8\%) & 407 (90.4\%) & $75(83.3 \%)$ & \\
\hline Yes & $130(7.3 \%)$ & $52(4.8 \%)$ & $12(14.5 \%)$ & $8(9.2 \%)$ & $43(9.6 \%)$ & $15(16.7 \%)$ & \\
\hline $\begin{array}{l}\text { Previous mental health } \\
\text { problems }\end{array}$ & & & & & & & $<0.001$ \\
\hline No & $1613(89.3 \%)$ & $1021(93.9 \%)$ & 57 (67.9\%) & 74 (83.1\%) & 401 (87.9\%) & $60(66.7 \%)$ & \\
\hline Yes & $193(10.7 \%)$ & $66(6.1 \%)$ & 27 (32.1\%) & 15 (16.9\%) & $55(12.1 \%)$ & $30(33.3 \%)$ & \\
\hline $\begin{array}{l}\text { Pre-pregnancy mental health } \\
\text { treatment }\end{array}$ & & & & & & & $<0.001$ \\
\hline No & $1622(90.4 \%)$ & $1007(93.3 \%)$ & 65 (78.3\%) & 77 (86.5\%) & $400(88.1 \%)$ & $73(81.1 \%)$ & \\
\hline Yes & $173(9.6 \%)$ & $72(6.7 \%)$ & $18(21.7 \%)$ & $12(13.5 \%)$ & $54(11.9 \%)$ & $17(18.9 \%)$ & \\
\hline Pre-pregnancy substance use & & & & & & & $<0.001$ \\
\hline No & $1141(63.1 \%)$ & 737 (67.8\%) & $38(44.7 \%)$ & $53(59.6 \%)$ & $267(58.6 \%)$ & $46(51.1 \%)$ & \\
\hline Yes & 666 (36.9\%) & $350(32.2 \%)$ & $47(55.3 \%)$ & $36(40.4 \%)$ & $189(41.4 \%)$ & $44(48.9 \%)$ & \\
\hline $\begin{array}{l}\text { Maternal anxiety (STAI) in } \\
\text { pregnancy }\end{array}$ & & & & & & & $<0.001$ \\
\hline No & $1421(78.9 \%)$ & 979 (90.4\%) & $29(34.1 \%)$ & 60 (67.4\%) & $317(69.8 \%)$ & $36(40.0 \%)$ & \\
\hline Yes & $380(21.1 \%)$ & $104(9.6 \%)$ & $56(65.9 \%)$ & $29(32.6 \%)$ & $137(30.2 \%)$ & $54(60.0 \%)$ & \\
\hline
\end{tabular}


Table 3 Sociodemographic, psychosocial and psychiatric predictors of maternal depression trajectories: EDEN cohort study, n=1334, 2003-2011, France adjusted OR [95\% Cl], multivariate polynomial logistic regression analysis

\begin{tabular}{|c|c|c|c|c|c|c|c|c|c|c|c|c|c|c|c|}
\hline \multirow[b]{2}{*}{ Determinants } & \multicolumn{3}{|c|}{$\begin{array}{l}\text { No symptoms } \\
{[n=832]}\end{array}$} & \multicolumn{3}{|c|}{$\begin{array}{l}\text { Symptoms in pregnancy only } \\
{[\mathrm{n}=56]}\end{array}$} & \multicolumn{3}{|c|}{$\begin{array}{l}\text { Symptoms in preschool only } \\
{[n=66]}\end{array}$} & \multicolumn{3}{|c|}{$\begin{array}{c}\text { Intermediate symptoms } \\
{[n=322]}\end{array}$} & \multicolumn{3}{|c|}{$\begin{array}{c}\text { Persistent high } \\
{[n=60]}\end{array}$} \\
\hline & OR & {$[95 \% \mathrm{Cl}]$} & $\begin{array}{c}P \\
\text { value }\end{array}$ & OR & {$[95 \% \mathrm{Cl}]$} & $\begin{array}{c}\mathrm{P} \\
\text { value }\end{array}$ & OR & {$[95 \% \mathrm{Cl}]$} & $\begin{array}{c}\mathrm{P} \\
\text { value }\end{array}$ & OR & {$[95 \% \mathrm{Cl}]$} & $\begin{array}{c}P \\
\text { value }\end{array}$ & OR & {$[95 \% \mathrm{Cl}]$} & $\begin{array}{c}P \\
\text { value }\end{array}$ \\
\hline \multicolumn{16}{|l|}{ Sociodemographic } \\
\hline Country of origin: Other & 1.00 & [ref.] & & 4.94 & {$[1.35$ - 18.07] } & .016 & .81 & {$[.35-7.67]$} & .529 & 1.65 & {$[.72-3.79]$} & .238 & 5.92 & {$[1.86-18.86]$} & .003 \\
\hline Number of children & 1.00 & [ref.] & & .99 & {$[.69-1.42]$} & .947 & 1.10 & {$[1.50-1.64]$} & .539 & .97 & {$[.82-1.15]$} & .729 & 1.04 & {$[.74-1.47]$} & .802 \\
\hline Educational level: $<12$ y & 1.00 & [ref.] & & 1.22 & {$[.60-2.46]$} & .588 & 1.05 & {$[.57-1.93]$} & .882 & 1.26 & {$[.91-1.74]$} & .170 & 1.28 & {$[.62-2.62]$} & .502 \\
\hline Employment: no & 1.00 & [ref.] & & .60 & {$[.12-2.93]$} & .529 & .59 & {$[.13-2.57]$} & .478 & .74 & {$[.32-1.67]$} & .465 & .47 & {$[.11-1.95]$} & .299 \\
\hline Partner educational level: $<12$ y & 1.00 & [ref.] & & 1.16 & {$[.59-2.30]$} & .670 & 1.99 & [1.09 - 3.65] & .025 & 1.14 & {$[.83-1.57]$} & .402 & .83 & {$[.41-1.65]$} & .588 \\
\hline Partner employment: no & 1.00 & [ref.] & & 1.21 & {$[.41-3.56]$} & .732 & 1.18 & {$[.41-3.40]$} & .754 & 1.31 & {$[.75-2.31]$} & .343 & 1.26 & {$[.44-3.61]$} & .668 \\
\hline Financial difficulties: yes & 1.00 & [ref.] & & 1.55 & {$[.62-3.86]$} & .348 & 1.35 & {$[.55-3.28]$} & .511 & 1.46 & {$[.89-2.40]$} & .138 & 1.37 & {$[.56-3.31]$} & .488 \\
\hline \multicolumn{16}{|l|}{ Psychosocial } \\
\hline$\geq 1$ life event during pregnancy: yes & 1.00 & [ref.] & & 1.73 & {$[.87-3.47]$} & .121 & 1.29 & {$[.66-2.52]$} & .455 & 1.47 & [1.03 - 2.09] & .035 & 1.40 & {$[.68-2.85]$} & .360 \\
\hline Work related stress: yes & 1.00 & [ref.] & & .80 & {$[.28-2.26]$} & .668 & 1.77 & {$[.85-3.69]$} & .125 & 1.46 & {$[.98-2.18]$} & .064 & .87 & {$[.32-2.36]$} & .777 \\
\hline Work Overinvestment: yes & 1.00 & [ref.] & & 1.57 & {$[.35-7.10]$} & .557 & 1.10 & {$[.58-2.06]$} & .774 & 2.04 & [1.49 - 2.78] & $<0.001$ & 4.78 & {$[2.23-10.23]$} & .008 \\
\hline$\geq 1$ Childhood adversity: yes & 1.00 & [ref.] & & 2.49 & [1.33 - 4.68] & .005 & 1.56 & {$[.88-2.75]$} & .125 & 1.11 & {$[.80-1.52]$} & .532 & 4.09 & {$[2.16-7.75]$} & $<0.001$ \\
\hline Partner any substance use: yes & 1.00 & [ref.] & & .79 & {$[.41-1.54]$} & .494 & .95 & {$[.54-1.68]$} & .870 & 1.04 & {$[.77-1.40]$} & .800 & 1.11 & {$[.58-2.14]$} & .743 \\
\hline Social support: no & 1.00 & [ref.] & & 4.31 & [1.52 - 12.25] & .006 & 1.05 & {$[.23-4.88]$} & .951 & .80 & {$[.32-2.01]$} & .633 & 2.13 & {$[.64-7.05]$} & .216 \\
\hline \multicolumn{16}{|l|}{ Psychiatric } \\
\hline Childhood behavior problems: yes & 1.00 & [ref.] & & 1.15 & {$[.39-3.41]$} & .799 & 1.64 & {$[.65-4.11]$} & .291 & 1.65 & {$[.95-2.86]$} & .077 & 1.72 & {$[.71-4.13]$} & .229 \\
\hline $\begin{array}{l}\text { Previous mental health problems: } \\
\text { yes }\end{array}$ & 1.00 & [ref.] & & 2.31 & {$[1.02-5.22]$} & .044 & 1.79 & {$[.80-3.98]$} & .155 & 1.15 & {$[.67-1.95]$} & .613 & 3.78 & [1.82 -7.85] & $<0.001$ \\
\hline $\begin{array}{l}\text { Pre-pregnancy mental health } \\
\text { treatment: yes }\end{array}$ & 1.00 & [ref.] & & 1.38 & {$[.53-3.59]$} & .506 & 2.58 & [1.18 - 5.65] & .018 & 1.78 & {$[1.09-2.93]$} & .022 & 1.60 & {$[.68-3.77]$} & .286 \\
\hline Pre-pregnancy substance use: yes & 1.00 & [ref.] & & 2.27 & [1.17 - 4.39] & .015 & 1.18 & {$[.65-2.12]$} & .587 & 1.19 & {$[.87-1.62]$} & .272 & 1.02 & {$[.52-2.00]$} & .946 \\
\hline Anxiety in pregnancy: yes & 1.00 & [ref.] & & 11.97 & [6.42 - 22.31] & $<0.001$ & 3.89 & [2.17 - 6.99] & $<0.001$ & 3.33 & {$[2.35-4.71]$} & $<0.001$ & 7.94 & [4.29 - 14.69] & $<0.001$ \\
\hline
\end{tabular}




\section{References}

Austin, M. P., Colton, J., Priest, S., Reilly, N. \& Hadzi-Pavlovic, D. (2013). The antenatal risk questionnaire (ANRQ): acceptability and use for psychosocial risk assessment in the maternity setting. Women and Birth 26, 17-25.

Austin, M. P., Hadzi-Pavlovic, D., Saint, K. \& Parker, G. (2005). Antenatal screening for the prediction of postnatal depression: validation of a psychosocial Pregnancy Risk Questionnaire. Acta Psychiatrica Scandinavia 112, 310-7.

Austin, M. P., Priest, S. R. \& Sullivan, E. A. (2008). Antenatal psychosocial assessment for reducing perinatal mental health morbidity. The Cochrane Database of Systematic Reviews, Cd005124. Banti, S., Mauri, M., Oppo, A., Borri, C., Rambelli, C., Ramacciotti, D., Montagnani, M. S., Camilleri, V., Cortopassi, S., Rucci, P. \& Cassano, G. B. (2011). From the third month of pregnancy to 1 year postpartum. Prevalence, incidence, recurrence, and new onset of depression. Results from the Perinatal Depression-Research and Screening Unit study. Comprehensive Psychiatry 52, 343-351. Betts, K. S., Williams, G. M., Najman, J. M. \& Alati, R. (2014). Maternal depressive, anxious, and stress symptoms during pregnancy predict internalizing problems in adolescence. Depression and Anxiety 31, 9-18.

Blondel, B., Supernant, K., Du Mazaubrun, C. \& Breart, G. (2006). [Trends in perinatal health in metropolitan France between 1995 and 2003: results from the National Perinatal Surveys]. Journal de Gynécologie Obstetrique et Biologie de la Réproduction 35, 373-87.

Campbell, S. B., Matestic, P., von Stauffenberg, C., Mohan, R. \& Kirchner, T. (2007). Trajectories of maternal depressive symptoms, maternal sensitivity, and children's functioning at school entry. Developmental Psychology 43, 1202-1215.

Carroll, J. C., Reid, A. J., Biringer, A., Midmer, D., Glazier, R. H., Wilson, L., Permaul, J. A., Pugh, P., Chalmers, B., Seddon, F. \& Stewart, D. E. (2005). Effectiveness of the Antenatal Psychosocial Health Assessment (ALPHA) form in detecting psychosocial concerns: a randomized controlled trial. Canadian Medical Association Journal 173, 253-9.

Cents, R. A. M., Diamantopoulou, S., Hudziak, J. J., Jaddoe, V. W. V., Hofman, A., Verhulst, F. C., Lambregtse-van den Berg, M. P. \& Tiemeier, H. (2013). Trajectories of maternal depressive symptoms predict child problem behaviour: The Generation R Study. Psychological Medicine 43, 1325.

Clark, C., Pike, C., McManus, S., Harris, J., Bebbington, P., Brugha, T., Jenkins, R., Meltzer, H., Weich, S. \& Stansfeld, S. (2012). The contribution of work and non-work stressors to common mental disorders in the 2007 Adult Psychiatric Morbidity Survey. Psychological Medicine 42, 829-42.

Coleman, V. H., Carter, M. M., Morgan, M. A. \& Schulkin, J. (2008). Obstetrician-gynecologists' screening patterns for anxiety during pregnancy. Depression and Anxiety 25, 114-23.

Connelly, C. D., Baker-Ericzen, M. J., Hazen, A. L., Landsverk, J. \& Horwitz, S. M. (2010). A model for maternal depression. Journal of Women's Health 19, 1747-57.

Cooklin, A. R., Rowe, H. J. \& Fisher, J. R. (2007). Employee entitlements during pregnancy and maternal psychological well-being. Australian and New Zealand Journal of Obstetrics and Gynaecology 47, 483-90.

Cox, J. L., Holden, J. M. \& Sagovsky, R. (1987). Detection of postnatal depression. Development of the 10-item Edinburgh Postnatal Depression Scale. The British Journal of Psychiatry 150, 782-6.

Darcy, J. M., Grzywacz, J. G., Stephens, R. L., Leng, I., Clinch, C. R. \& Arcury, T. A. (2011). Maternal depressive symptomatology: 16-month follow-up of infant and maternal health-related quality of life. Journal of the American Board of Family Medicine 24, 249-57.

Dennis, C. L. \& Dowswell, T. (2013). Psychosocial and psychological interventions for preventing postpartum depression. The Cochrane Database of Systematic Reviews 2, Cd001134.

Drouillet, P., Forhan, A., De Lauzon-Guillain, B., Thiebaugeorges, O., Goua, V., Magnin, G., Schweitzer, M., Kaminski, M., Ducimetiere, P. \& Charles, M. A. (2009). Maternal fatty acid intake and fetal growth: evidence for an association in overweight women. The 'EDEN mother-child' cohort 
(study of pre- and early postnatal determinants of the child's development and health). The British Journal of Nutrition 101, 583-91.

Drouillet, P., Kaminski, M., De Lauzon-Guillain, B., Forhan, A., Ducimetiere, P., Schweitzer, M., Magnin, G., Goua, V., Thiebaugeorges, O. \& Charles, M. A. (2008). Association between maternal seafood consumption before pregnancy and fetal growth: evidence for an association in overweight women. The EDEN mother-child cohort. Paediatric and Perinatal Epidemiology 23, 76-86.

Dunkel Schetter, C. \& Tanner, L. (2012). Anxiety, depression and stress in pregnancy: implications for mothers, children, research, and practice. Current Opinions in Psychiatry 25, 141-8.

Ertel, K. A., Rich-Edwards, J. W. \& Koenen, K. C. (2011). Maternal depression in the United States: nationally representative rates and risks. Journal of Women's Health 20, 1609-17.

Essex, M. J., Klein, M. H., Miech, R. \& Smider, N. A. (2001). Timing of initial exposure to maternal major depression and children's mental health symptoms in kindergarten. The British Journal of Psychiatry 179, 151-156.

Farrell, M., Howes, S., Bebbington, P., Brugha, T., Jenkins, R., Lewis, G., Marsden, J., Taylor, C. \& Meltzer, H. (2003). Nicotine, alcohol and drug dependence, and psychiatric comorbidity-results of a national household survey. International Review of Psychiatry 15, 50-6.

Fihrer, I., McMahon, C. A. \& Taylor, A. J. (2009). The impact of postnatal and concurrent maternal depression on child behaviour during the early school years. Journal of Affective Disorders 119, 116123.

Fuhrer, R. \& Rouillon, F. (1989). La version française de l'échelle CES-D [French version of the CES-D]. Psychiatrie Psychobiologie 4, 163-166.

Gaillard, A., Le Strat, Y., Mandelbrot, L., Keita, H. \& Dubertret, C. (2014). Predictors of postpartum depression: Prospective study of 264 women followed during pregnancy and postpartum. Psychiatry Research 28, 341-6

Giallo, R., Cooklin, A. \& Nicholson, J. M. (2014). Risk factors associated with trajectories of mothers' depressive symptoms across the early parenting period: an Australian population-based longitudinal study. Archives of Women's Mental Health 17,115-25

Goodman, J. H. \& Tyer-Viola, L. (2010). Detection, treatment, and referral of perinatal depression and anxiety by obstetrical providers. Journal of Womens Health 19, 477-90.

Goodman, S. H. (2007). Depression in mothers. Annual Review of Clinical Psychology 3, 107-35. Guedeney, N. \& Fermanian, J. (1998). Validation study of the French version of the Edinburgh Postnatal Depression Scale (EPDS): new results about use and psychometric properties. European Psychiatry 13, 83-9.

Heron, J., O'Connor, T. G., Evans, J., Golding, J. \& Glover, V. (2004). The course of anxiety and depression through pregnancy and the postpartum in a community sample. Journal of Affective Disorders 80, 65-73.

Horwitz, S. M., Briggs-Gowan, M. J., Storfer-Isser, A. \& Carter, A. S. (2009). Persistence of maternal depressive symptoms throughout the early years of childhood. Journal of Women's Health 18, 63745.

Johnson, M., Schmeid, V., Lupton, S. J., Austin, M. P., Matthey, S. M., Kemp, L., Meade, T. \& Yeo, A. E. (2012). Measuring perinatal mental health risk. Archives of Womens Mental Health 15, 375-86. Joiner, T. E., Walker, R. L., Pettit, J. W., Perez, M. \& Cukrowicz, K. C. (2005). Evidence-based assessment of depression in adults. Psychological Assessment 17, 267-277.

Jones, B. L. \& Nagin, D. S. (2007). Advances in group-based trajectory modeling and an SAS procedure for estimating them. Sociological Methods \& Research 35, 542-571.

Jones, B. L., Nagin, D. S. \& Roeder, K. (2001). A SAS procedure based on mixture models for estimating developmental trajectories. Sociological Methods \& Research 29, 374-393.

Koleva, H., Stuart, S., O'Hara, M. W. \& Bowman-Reif, J. (2011). Risk factors for depressive symptoms during pregnancy. Archives of Women's Mental Health 14, 99-105.

Le Strat, Y., Dubertret, C. \& Le Foll, B. (2011). Prevalence and correlates of major depressive episode in pregnant and postpartum women in the United States. Journal of Affective Disorders 135, 128-138. 
Lindert, J., Schouler-Ocak, M., Heinz, A. \& Priebe, S. (2008). Mental health, health care utilisation of migrants in Europe. European Psychiatry 23 Suppl 1, 14-20.

Markon, K. E., Chmielewski, M. \& Miller, C. J. (2011). The reliability and validity of discrete and continuous measures of psychopathology: a quantitative review. Psychological Bulletin 137, 856-79.

Miyake, Y., Tanaka, K., Sasaki, S. \& Hirota, Y. (2011). Employment, income, and education and risk of postpartum depression: the Osaka Maternal and Child Health Study. Journal of Affective Disorders 130, 133-7.

Mora, P. A., Bennett, I. M., Elo, I. T., Mathew, L., Coyne, J. C. \& Culhane, J. F. (2009). Distinct trajectories of perinatal depressive symptomatology: evidence from growth mixture modeling. American Journal of Epidemiology 169, 24-32.

Nagin, D. (1999). Analyzing developmental trajectories: A semiparametric, group-based approach. Psychological Methods 4, 139-157.

Nagin, D. (2005). Group-based modeling of development. Harvard University Press: Cambridge, MA. Najman, J. M., Andersen, M. J., Bor, W., O'Callaghan, M. J. \& Williams, G. M. (2000). Postnatal depression-myth and reality: maternal depression before and after the birth of a child. Social Psychiatry and Psychiatric Epidemiology 35, 19-27.

O'Hara, M. W. \& McCabe, J. E. (2013). Postpartum depression: current status and future directions. Annual Review of Clinical Psychology 9, 379-407.

Pereira, A. T., Marques, M., Soares, M. J., Maia, B. R., Bos, S., Valente, J., Nogueira, V., Roque, C., Madeira, N. \& Macedo, A. (2014). Profile of depressive symptoms in women in the perinatal and outside the perinatal period: similar or not? Journal of Affective Disorders 166, 71-8.

Radloff, L. S. (1977). The CES-D Scale: A self-report depression scale for research in the general population. Applied Psychological Measurement 1, 385-401.

Ruhm, C. J. \& Teague, J. L. (1998). Parental leave policies in Europe and North America. In Women in the labour market. Volume 2. (ed. M. A. Ferber), pp. 133-156. Elgar Reference Collection:

Cheltenham, U.K. and Northampton, Mass.

Seimyr, L., Welles-Nyström, B. \& Nissen, E. (2013). A history of mental health problems may predict maternal distress in women postpartum. Midwifery 29, 122-131.

Seto, M., Cornelius, M. D., Goldschmidt, L., Morimoto, K. \& Day, N. L. (2005). Long-term effects of chronic depressive symptoms among low-income childrearing mothers. Maternal and Child Health Journal 9, 263-271.

Siegrist, J. (2008). Chronic psychosocial stress at work and risk of depression: evidence from prospective studies. European Archives of Psychiatry and Clinical Neuroscience 258 Suppl 5, 115-9. Siegrist, J., Starke, D., Chandola, T., Godin, I., Marmot, M., Niedhammer, I. \& Peter, R. (2004). The measurement of effort-reward imbalance at work: European comparisons. Social Science \& Medicine 58, 1483-1499.

Skipstein, A., Janson, H., Kjeldsen, A., Nilsen, W. \& Mathiesen, K. S. (2012). Trajectories of maternal symptoms of depression and anxiety over 13 years: the influence of stress, social support, and maternal temperament. BMC Public Health 12, 1120.

Skipstein, A., Janson, H., Stoolmiller, M. \& Mathiesen, K. S. (2010). Trajectories of maternal symptoms of anxiety and depression. A 13-year longitudinal study of a population-based sample. BMC Public Health 10, 589.

Skouteris, H., Wertheim, E. H., Rallis, S., Milgrom, J. \& Paxton, S. J. (2009). Depression and anxiety through pregnancy and the early postpartum: an examination of prospective relationships. Journal of Affective Disorders 113, 303-8.

Solomon, L. J., Higgins, S. T., Heil, S. H., Badger, G. J., Mongeon, J. A. \& Bernstein, I. M. (2006). Psychological symptoms following smoking cessation in pregnant smokers. Journal of Behavioral Medicine 29, 151-60.

Spielberger, C. D., Gorsuch, R. L., Lushene, P. R., Vagg, P. R. \& Jacobs, A. G. (1983). Manual for the State-Trait Anxiety Inventory (Form Y). Consulting Psychologists Press, Inc.: Palo Alto. 
Sutter-Dallay, A. L., Cosnefroy, O., Glatigny-Dallay, E., Verdoux, H. \& Rascle, N. (2012). Evolution of perinatal depressive symptoms from pregnancy to two years postpartum in a low-risk sample: The MATQUID cohort. Journal of Affective Disorders 139, 23-29.

Sutter-Dallay, A. L., Giaconne-Marcesche, V., Glatigny-Dallay, E. \& Verdoux, H. (2004). Women with anxiety disorders during pregnancy are at increased risk of intense postnatal depressive symptoms: a prospective survey of the MATQUID cohort. European Psychiatry 19, 459-63.

Sutter-Dallay, A. L., Murray, L., Dequae-Merchadou, L., Glatigny-Dallay, E., Bourgeois, M. L. \& Verdoux, H. (2011). A prospective longitudinal study of the impact of early postnatal vs. chronic maternal depressive symptoms on child development. European Psychiatry 26, 484-489.

Teissedre, F. \& Chabrol, H. (2004). [A study of the Edinburgh Postnatal Depression Scale (EPDS) on 859 mothers: detection of mothers at risk for postpartum depression]. Encephale 30, 376-81.

Turney, K. (2012). Pathways of disadvantage: explaining the relationship between maternal depression and children's problem behaviors. Social Science Research 41, 1546-1564.

van Vegchel, N., de Jonge, J., Bosma, H. \& Schaufeli, W. (2005). Reviewing the effort-reward imbalance model: drawing up the balance of 45 empirical studies. Social Science \& Medicine 60 , 1117-1131.

Vänskä, M., Punamäki, R. L., Tolvanen, A., Lindblom, J., Flykt, M., Unkila-Kallio, L., Tiitinen, A., Repokari, L., Sinkkonen, J. \& Tulppala, M. (2011). Maternal pre- and postnatal mental health trajectories and child mental health and development: Prospective study in a normative and formerly infertile sample. International Journal of Behavioral Development 35, 517-531.

Viau, P. A., Padula, C. A. \& Eddy, B. (2002). An exploration of health concerns \& health-promotion behaviors in pregnant women over age 35. The American Journal of Maternal Child Nursing 27, 32834.

Vliegen, N., Casalin, S. \& Luyten, P. (2014). The course of postpartum depression: A review of longitudinal studies. Harvard Review of Psychiatry 22, 1-22.

Wang, L., Wu, T., Anderson, J. L. \& Florence, J. E. (2011). Prevalence and risk factors of maternal depression during the first three years of child rearing. Journal of Women's Health 20, 711-8.

Woolhouse, H., Gartland, D., Mensah, F. \& Brown, S. (2014). Maternal depression from early pregnancy to 4 years postpartum in a prospective pregnancy cohort study: implications for primary health care. BJOG: an International journal of Obstetrics and Gynaecology doi: 10.1111/14710528.12837

Wynter, K., Rowe, H. \& Fisher, J. (2013). Common mental disorders in women and men in the first six months after the birth of their first infant: a community study in Victoria, Australia. Journal of Affective Disorders 151, 980-5.

Zhu, S. H. \& Valbo, A. (2002). Depression and smoking during pregnancy. Addictive Behaviors 27, 649-58. 